\title{
The effect of physical therapy and rehabilitation modalities on sleep quality in patients with primary knee osteoarthritis: A single-blind, prospective, randomized-controlled study
}

\author{
Elif Umay Altaş@, Ümit Seçil Demirdal@ \\ Department of Physical Medicine and Rehabilitation, Katip Çelebi University Atatürk Training and Research Hospital, Izmir, Turkey \\ Received: April 06, 2018 Accepted: January 23, 2019 Published online: March 03, 2020
}

\begin{abstract}
Objectives: In this study, we aimed to evaluate the effect of physical therapy modalities on pain, sleep, mental status, and quality of life of patients with osteoarthritis (OA).

Patients and methods: Between January 2017 and June 2017, a total of 40 patients ( 9 males, 31 females; mean age $56.6 \pm 8.9$ years; range, 40 to 70 years) who were diagnosed with knee OA according to the American College of Rheumatology (ACR) criteria and were in KellgrenLawrence Grade 2-3 were included in the study. The patients were divided into two groups equally. Both groups received 15 sessions of exercise therapy, whereas the intervention group also received 10 consecutive physical therapy sessions in the form of hot pack, therapeutic ultrasound (US), and transcutaneous electrical nerve stimulation (TENS) by a single physiotherapist. Isometric and isotonic exercises were planned as 10 reps for three times a day as a home-based program. Clinical assessments were performed using the visual analog scale (VAS), Western Ontario and McMaster Universities Osteoarthritis Index (WOMAC), Beck Depression Inventory (BDI), Pittsburg Sleep Quality Index (PSQI), Epworth Sleepiness Scale (ESS), and Short Form 36 (SF-36) before and after treatment.

Results: Pre-treatment VAS, ESS, PQSI, BDI, WOMAC, and SF-36 scores showed no significant difference between the groups, whereas post-treatment scores showed a significant difference in the intervention group $(\mathrm{p}<0.05)$. The difference between the pre- and post-treatment VAS, ESS, PQSI, BDI, WOMAC, and SF-36 scores were significantly higher in the intervention group, compared to the controls ( $<<0.05$ ).

Conclusion: Our study results show positive effects of exercise and physical therapy modalities on pain, disease activity, sleep quality, depression, and quality of life in knee OA patients.
\end{abstract}

Keywords: Physical therapy modals, primary knee osteoarthritis, sleep quality.

Osteoarthritis (OA) is the most common subtype of arthritis mainly characterized by pain and limitations in movement due to joint degeneration. Its lifetime prevalence is $44.7 \%$, and the most common OA type is gonarthrosis (knee OA). ${ }^{[1]}$ In the United States, knee OA affects an estimated 46 million of adults and radiographic evidence of knee OA increases with age from $27 \%$ in those younger than 70 years old to $44 \%$ in octogenarians. ${ }^{[2]}$ Although the data is limited in Turkey, knee OA prevalence has been estimated as $5.3 \%$ in Havsa district of Edirne and $20.9 \%$ in a Bayrakli Adalet district of Izmir in patients aged over 40 years. ${ }^{[3,4]}$

Osteoarthritis is a slowly progressive, chronic, degenerative disease characterized by reshaping of the periarticular bone due to joint cartilage loss which causes damage in the adjacent bones and clinical and radiographic findings in the joints. Its etiology is multifactorial and sex, age, obesity, hereditary disposition, reproductive events, and local mechanical factors play a role in the etiology. Stiffness, particularly in the morning, limited joint movements, worsened

\footnotetext{
Corresponding author: Elif Umay Altaş, MD. Katip Çelebi Üniversitesi Atatürk Eğitim ve Araştırma Hastanesi Fizik Tedavi ve Rehabilitasyon Kliniği, 35360 Basın Sitesi, İzmir, Türkiye. e-mail: elifumayaslan@hotmail.com 
quality of life (QoL), depression, and fatigue can be seen in OA. ${ }^{[5]}$

Most common clinical findings, which are pain and disability, can become persistent in late terms of the disease, affecting sleep quality, mental health, and social functioning of the patient adversely. ${ }^{[6]}$ Pain is ongoing, all through the night, in more than half of knee OA patients, and patients usually have complaints of sleep disorders such as poor sleep quality, frequent awakenings, and frequent changes in sleep patterns. In addition, sleep disorders are associated with fatigue during daytime and impaired QoL. ${ }^{[7]}$

The main goals of knee OA treatment are to control the pain, to preserve joint functions, to obtain functional independence, and to increase QoL. Treatment of knee OA includes nonpharmacological, pharmacological, and even surgical treatment in severe cases. ${ }^{[7]}$ Non-pharmacological therapies include physical therapy modalities such as exercise and surface heat applications, transcutaneous electrical nerve stimulation (TENS), and therapeutic ultrasound (US), which are frequently used. ${ }^{[8]}$ Electric currents produced by the TENS machine decrease pain by stimulating the nerves. In a study, Cheing et al. ${ }^{[9]}$ reported reduced pain even after one session and this analgesic effect sustained for 24 hours in some of the patients. In addition, US is the most commonly used physical therapy modality as a deep tissue warmer. Thermal effects of US include increasing the metabolic speed, nerve transmission, circulation, and soft tissue flexibility, while controlling pain and muscle spasms. It has also a chondroprotective effect on the osteoarthritic cartilage and is one of the safest treatment options in knee OA. ${ }^{[10]}$ However, exercise is the main component of non-pharmacological therapies. Progressive resistance exercise has been shown to improve overall physical activity levels, while strengthening exercises can reduce pain in patients with early knee OA. ${ }^{[1]}$

Although the effectiveness of physical therapy modalities in knee OA has been evaluated in many studies, there is a very limited number of studies in the literature discussing their effects on sleep quality in knee OA patients. In the present study, we, therefore, aimed to evaluate the effect of physical therapy modalities on pain, sleep, mental status, and QoL of patients with OA and to investigate the possible relationship between sleep quality and pain, psychological status, and QoL of OA patients.

\section{PATIENTS AND METHODS}

This single-blind, prospective, randomizedcontrolled study was conducted at Katip Çelebi University Atatürk Training and Research Hospital Physical Therapy and Rehabilitation outpatient clinic between January 2017 and June 2017. A total of 40 patients ( 9 males, 31 females; mean age 56.6 \pm 8.9 years; range, 40 to 70 years) who were admitted with knee pain and diagnosed with knee OA according to the 1986 American College of Rheumatology (ACR) criteria and were in Kellgren-Lawrence (KL) Grade 2-3 were included in the study. All patients underwent a detailed physical examination and radiographic evaluation. Patients with knee effusion, secondary OA, severe knee trauma history within the past six months, previous intraarticular hyaluronic acid or steroid injection, meniscal or connective tissue damage, and those receiving physical therapy within the past year for knee pain were excluded from the study. Those with joint pathologies other than knee $\mathrm{OA}$ in the lower extremity, previous lower extremity surgery including knee surgery, severe circulatory problems in lower extremity, restless leg syndrome, fibromyalgia, inflammatory disease, active infectious disease, severe systemic disease such as asthma or cardiac failure, neurological disease, psychiatric disease, malignancy or pregnant women and those with a pacemaker were also excluded. A written informed consent was obtained from each patient. The study protocol was approved by the Katip Çelebi University Atatürk Training and Research Hospital Ethics Committee. The study was conducted in accordance with the principles of the Declaration of Helsinki.

The patients were randomly and equally allocated to either intervention or control group with a 1:1 ratio using non-stratified block randomization. We used a web-based randomization software (Randomization. com; www.randomization.com) and prepared a random list before the study. Randomization was performed using this list. Of a total of 40 patients, 20 were assigned to the intervention group and 20 were assigned to the control group. In the intervention group, 10 therapy sessions using the same instruments and exercise treatment five days a week and a single session each day were performed by a single physiotherapist. The control group only received exercise treatment. Hot pack (HP) was used as a surface warmer for $20 \mathrm{~min}$ in the intervention group. Also, TENS was applied using the Enraf (Enraf-Nonius B.V., Rotterdam, Holland) TENS instrument with $0-100 \mathrm{~Hz}$, dual $5 \times 7 \mathrm{~cm}$ electrodes for $20 \mathrm{~min}$. The patient was laid in the supine position 
and two surface electrodes were used on upper part of the knee, while two surface electrodes were used on the lower part of the knee in full extension. The current intensity used was set as not to cause muscle contractions and based on the patient perception of "strong, but tolerable". As deep warmer, therapeutic US was applied for five min in the continuous mode at 1.5 watt $/ \mathrm{cm}^{2}$ with $100 \%$ productivity in $1 \mathrm{mHz}$. The Enraf (Enraf-Nonius B.V., Rotterdam, Holland) US with a $3-\mathrm{cm}^{2}$ head was used. ${ }^{[12,13]}$ Similarly, it was applied in the supine position with knees extended into the periarticular area in the circular motions.

Both groups received the same home-based exercise program as in 30 sessions with 10 reps a day for three times a week. Exercise program was demonstrated and explained by a single physiotherapist. Visual exercise guides were also provided for the patients. Exercise program consisted of isometric and isotonic exercises. The patient was asked to insert a rolled towel under his/her knee, while sitting upright on the bed and push his/her knees toward the ground and, then, relax the knee and, then, to put the same towel between the knees and squeeze it for five sec and release. Another exercise was to lift his/her leg $10-\mathrm{cm}$ above the ground, while lying in the supine position and one knee bent for five sec and, then, lower it back down. In addition, the patient was asked to raise his/her knee by $90^{\circ}$ while sitting on a chair and wait for five sec and, then, lower the knee and to add $0.5 \mathrm{~kg}$ in the second and $1 \mathrm{~kg}$ weight in the third week. Hamstring stretching exercises were also prescribed as flexing the body during ankle dorsiflexion and lying ankle dorsi- and plantar flexion exercises. ${ }^{[14]}$

All patients were allowed to use paracetamol at a dose $\leq 3,000 \mathrm{mg} /$ day for pain during the assessment. ${ }^{[15]}$ However, they were instructed not to use any other analgesics except for paracetamol. In addition, all patients were allowed to use other medications for their concomitant systemic diseases.

\section{Assessment scales}

Demographic data including age, sex, marital status, body mass index (BMI), and disease duration were recorded. In patients with pain in both knees, the most painful side was recorded (right or left). In addition, anteroposterior knee X-rays were evaluated, and progressive disease was recorded according to the $\mathrm{KL}$ radiographic grading scale which is based on the osteophyte formation, narrowing in the joint space, and the presence of sclerosis and joint deformity (Grade 0: Normal; Grade 1: Doubtful OA; Grade 2: Minimal OA; Grade 3: Moderate OA; and Grade 4: Severe OA). ${ }^{[16]}$

\begin{tabular}{|c|c|c|c|c|c|c|c|}
\hline & \multicolumn{3}{|c|}{ Intervention group $(n=20)$} & \multicolumn{3}{|c|}{ Control group $(\mathrm{n}=20)$} & \multirow[b]{2}{*}{$p$} \\
\hline & $\mathrm{n}$ & $\%$ & Mean \pm SD & $\mathrm{n}$ & $\%$ & Mean \pm SD & \\
\hline Age (year) & & & $57.6 \pm 8.7$ & & & $55.5 \pm 9.6$ & 0.42 \\
\hline Body mass index $\left(\mathrm{kg} / \mathrm{m}^{2}\right)$ & & & $32.0 \pm 4.1$ & & & $31.3 \pm 4.4$ & 0.53 \\
\hline Duration of symptoms (month) & & & $3.4 \pm 1.3$ & & & $2.9 \pm 1.3$ & 0.20 \\
\hline Gender & & & & & & & 0.45 \\
\hline Female & 14 & 70 & & 17 & 85 & & \\
\hline Male & 6 & 30 & & 3 & 15 & & \\
\hline Marital status & & & & & & & 0.69 \\
\hline Married & 15 & 75 & & 17 & 85 & & \\
\hline Not-married & 5 & 25 & & 3 & 15 & & \\
\hline Occupation & & & & & & & 0.14 \\
\hline Housewife & 9 & 45 & & 14 & 70 & & \\
\hline Retired & 5 & 25 & & 1 & 5 & & \\
\hline Worker & 6 & 30 & & 5 & 25 & & \\
\hline Affected side & & & & & & & 1.00 \\
\hline Right & 10 & 50 & & 10 & 50 & & \\
\hline Left & 10 & 50 & & 10 & 50 & & \\
\hline Grade & & & & & & & 0.34 \\
\hline 2 & 10 & 50 & & 13 & 65 & & \\
\hline 3 & 10 & 50 & & 7 & 35 & & \\
\hline
\end{tabular}


The pain severity was assessed by visual analog scale (VAS), functional status by the Western Ontario and McMaster Universities Osteoarthritis Index (WOMAC), psychological status by the Beck Depression Inventory (BDI), sleep quality by the Pittsburgh Sleep Quality Index (PSQI), daytime sleepiness by the Epworth Sleep Scale (ESS), and QoL by the Short Form 36 (SF-36). All assessments were by a single researcher prior to treatment and 20 days after the treatment. The researcher was blinded to the group and treatment allocation.

The VAS is a scale used for the evaluation of pain severity. ${ }^{[17]}$ The scale is a $10-\mathrm{cm}$ line with the leftmost part showing no pain to the rightmost part showing maximum pain. All patients were asked to mark the most appropriate statement on the line according to the pain they experienced within the last week.

The WOMAC is a scale to assess disease-related functional status and disability. ${ }^{[18]}$ It consists of three parts with 24 simple questions in total. Five questions are related to pain (WOMAC-A), two questions to morning stiffness (WOMAC-B), and the remaining 17 questions to physical condition (WOMAC-C). Each question is scored using 4-point Likert scale $(0=$ None, $1=$ Mild, $2=$ Moderate, $3=$ Severe, $4=$ Very severe $)$. Higher scores indicate severe pain, increased stiffness, and functional failure. ${ }^{[19]}$

The BDI is useful tool for the evaluation of psychological status of patients. It consists of 17 questions with each question scoring between $0-3$. The maximum score is 63 . Scores of $\leq 16$ are considered normal, whereas scores $>17$ indicate clinical depression. ${ }^{[20]}$

In this study, sleep quality was evaluated using the PSQI and ESS. The PSQI is a test which assesses sleep quality, sleep disorder pattern, and severity within the past month. It consists of 24 questions with 19 feedback questions and it gives scores of seven components

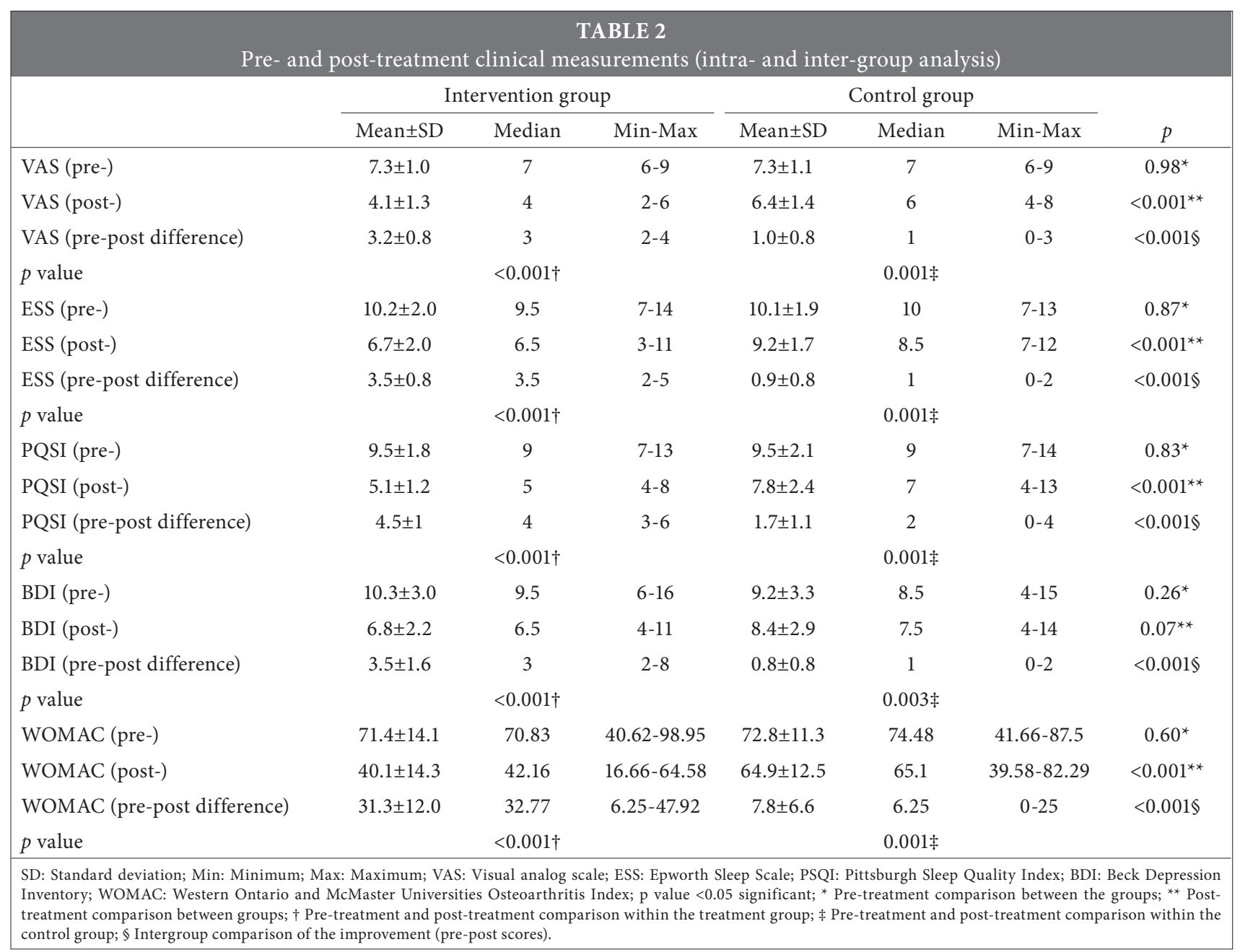


including subjective sleep quality, delayed sleep, sleeping period, sleep productivity, sleep disorders, use of sleep medication, daytime sleepiness. Each question is scored between $0-3$, and total PQSI is calculated between 0-21 with seven components. Higher scores indicate low sleep quality. Global scores of $\geq 5$ indicate a clinically significant sleeping disorder. The validity and reliability studies of the scale were conducted by Agargun et al. ${ }^{[21]}$ in the Turkish population.

The ESS is a simple and widely used scale which consists of eight questions with each question scored between 0-3. It measures overall level of daytime sleepiness during daily activities at a particular time. Total score is expected to be 10 or below in healthy

\begin{tabular}{|c|c|c|c|c|c|c|c|}
\hline \multicolumn{8}{|c|}{$\begin{array}{l}\text { TABLE } 3 \\
\text { Pre- and post-treatment SF-36 scores (intra- and inter-group analysis) }\end{array}$} \\
\hline & \multicolumn{3}{|c|}{ Intervention group } & \multicolumn{3}{|c|}{ Control group } & \multirow[b]{2}{*}{$p$} \\
\hline & Mean \pm SD & Median & Min-Max & Mean \pm SD & Median & Min-Max & \\
\hline Physical function (pre-) & $65.3 \pm 18.5$ & 65 & 20-95 & $50.3 \pm 15.8$ & 50 & $25-80$ & $0.013^{*}$ \\
\hline Physical function (post-) & $83 \pm 13.8$ & 85 & $35-100$ & $59 \pm 13.6$ & 62.5 & $40-80$ & $<0.001^{\star *}$ \\
\hline Physical function (pre-post difference) & $17.8 \pm 12.5$ & 17.5 & $0-45$ & $8.8 \pm 10.5$ & 5 & $-10-35$ & $0.027 \S$ \\
\hline$p$ value & & $<0.001 \dagger$ & & & $0.003 \ddagger$ & & \\
\hline Role physical (pre-) & $21.3 \pm 33.7$ & 0 & $0-100$ & $20 \pm 26.4$ & 12.5 & $0-100$ & $0.71^{\star}$ \\
\hline Role physical (post-) & $66.3 \pm 29.6$ & 62.5 & $25-100$ & $28.75 \pm 3$ & 25 & $0-100$ & $<0.001^{* *}$ \\
\hline Role physical (pre-post difference) & $45 \pm 28.8$ & 50 & $0-100$ & $8.8 \pm 14.7$ & 0 & $0-50$ & $<0.001 \S$ \\
\hline$p$ value & & $<0.001 \dagger$ & & & $0.020 \ddagger$ & & \\
\hline Pain (pre-) & $35.6 \pm 12.7$ & 36.5 & $10-62$ & $38.7 \pm 17.9$ & 41 & $10-74$ & $0.63^{*}$ \\
\hline Pain (post-) & $55.6 \pm 12.6$ & 52 & $31-74$ & $45.4 \pm 15.1$ & 41 & $30-74$ & $0.012^{\star *}$ \\
\hline Pain (pre-post difference) & $20 \pm 10.6$ & 21 & $0-49$ & $6.8 \pm 7.0$ & 8.5 & $0-20$ & $<0.001 \S$ \\
\hline$p$ value & & $<0.001 \dagger$ & & & $0.003 \ddagger$ & & \\
\hline General health (pre-) & $26.9 \pm 13.2$ & 30 & $0-52$ & $33.1 \pm 13.5$ & 35 & $10-61$ & $0.19^{*}$ \\
\hline General health (post-) & $43.8 \pm 9.2$ & 43.5 & $25-56$ & $40.9 \pm 16.7$ & 40 & $20-76$ & $0.28^{\star *}$ \\
\hline General health (pre-post difference) & $17.0 \pm 11$ & 15 & $0-41$ & $7.8 \pm 9.1$ & 5 & $0-36$ & $<0.001 \S$ \\
\hline$p$ value & & $<0.001 \dagger$ & & & $0.001 \ddagger$ & & \\
\hline Vitality (pre-) & $42.8 \pm 20.7$ & 47.5 & $15-75$ & $41.8 \pm 19.1$ & 40 & $15-75$ & $1.00^{*}$ \\
\hline Vitality (post-) & $62 \pm 15.3$ & 65 & $35-80$ & $40 \pm 13.7$ & 37.5 & $20-60$ & $<0.001^{\star *}$ \\
\hline Vitality (pre-post difference) & $19.3 \pm 15.3$ & 17.5 & $-10-50$ & $-1.8 \pm 12.4$ & 0 & $-40-10$ & $<0.001 \S$ \\
\hline$p$ value & & $<0.001 \dagger$ & & & $0.908 \ddagger$ & & \\
\hline Social function (pre-) & $53.1 \pm 19.8$ & 50 & $12.5-87.5$ & $45 \pm 24.1$ & 37.5 & $12.5-100$ & $0.09^{\star}$ \\
\hline Social function (post-) & $76.2 \pm 17.1$ & 75 & $50-100$ & $50 \pm 21.5$ & 43.75 & $25-100$ & $<0.001^{\star *}$ \\
\hline Social function (pre-post difference) & $23.1 \pm 13.6$ & 24.75 & $0-50$ & $5.0 \pm 6.3$ & 0 & $0-12.5$ & $<0.001$ \$ \\
\hline$p$ value & & $<0.001 \dagger$ & & & $0.001 \ddagger$ & & \\
\hline Role emotion (pre-) & $23.1 \pm 26.4$ & 16.5 & $0-66$ & $29.8 \pm 30.2$ & 33 & $0-100$ & $0.50^{*}$ \\
\hline Role emotion (post-) & $79.7 \pm 22.9$ & 83 & $33-100$ & $47.9 \pm 22.8$ & 33 & $0-100$ & $<0.001^{* *}$ \\
\hline Role emotion (pre-post difference) & $56.6 \pm 26.6$ & 50 & $33-100$ & $18.2 \pm 16.8$ & 33 & $0-33$ & $<0.001 \S$ \\
\hline$p$ value & & $<0.001 \dagger$ & & & $0.002 \ddagger$ & & \\
\hline Mental health (pre-) & $55.6 \pm 10.2$ & 54 & $40-80$ & $50.2 \pm 19.4$ & 48 & $28-88$ & $0.07^{\star}$ \\
\hline Mental health (post-) & $69 \pm 9.4$ & 66 & $52-88$ & $56 \pm 16.8$ & 52 & $32-88$ & $0.007^{\star *}$ \\
\hline Mental health (pre-post difference) & $13.4 \pm 5.6$ & 12 & $4-28$ & $5.8 \pm 7.1$ & 4 & $0-24$ & $<0.001 \S$ \\
\hline$p$ value & & $<0.001 \dagger$ & & & $0.001 \ddagger$ & & \\
\hline
\end{tabular}


individuals. Higher scores indicate higher sleep propensity in daily life. The validity and reliability studies of the scale were performed in the Turkish population. ${ }^{[22]}$

The quality of life was assessed using the SF-36 which is the most widely used general health scale. The SF-36 consists of eight subscales: physical function, physical capacity (role), emotional status, social function, general health, mental health, vitality (energy), and bodily pain. Physical health score is calculated by combining physical function, physical role, and general health scores. Mental health score is calculated by combining vitality, social function, emotional status, and mental health subscale scores. On a $0-100$ scale, 0 indicates the worst QoL, whereas 100 indicates the best QoL. The validity and reliability studies of the scale were performed in the Turkish population. ${ }^{[23]}$

\section{Statistical analysis}

The sample size was calculated using the $G^{*}$ Power version 3.1 software (Heinrich-Heine-Universität Düsseldorf, Düsseldorf, Germany). Accordingly, a total of 40 patients were needed to detect a significant difference in the changes of VAS scores in the intervention group $(4.1 \pm 1.5)$ and control group $(2.5 \pm 1.5)$ with a type 1 error of 0.05 and a power of
$90 \%$. Therefore, a total of 40 patients were included in the study.

Statistical analysis was performed using the IBM SPSS version 24.0 software (IBM Corp., Armonk, NY, USA). Descriptive data were expressed in mean \pm standard deviation (SD), median (min-max) or number and frequency. The Fisher's exact test and Pearson chisquare test were used to compare categorical variables between the groups, while the Mann-Whitney $U$ test was used for continuous variables. Pre- and posttreatment values were compared using the Wilcoxon signed-rank test. The relationship between variables was assessed using the Spearman correlation analysis. Repeated measures analysis of covariance (ANCOVA) was performed to adjust the effect of potential confounders such as age and sex. A $p$ value of $<0.05$ was considered statistically significant.

\section{RESULTS}

In all patients included in the study, the mean disease duration was $3.13 \pm 1.3$ (range, 1 to 5) years. None of the patients in the intervention group needed to receive paracetamol during the study. However, in the control group, two patients reported the use of paracetamol (a 69-year-old male patient needed to receive $1,500 \mathrm{mg} / \mathrm{day}$ from the third day of exercise

\begin{tabular}{|c|c|c|c|c|}
\hline \multirow[b]{4}{*}{ Variable } & \multirow{2}{*}{\multicolumn{2}{|c|}{$\begin{array}{l}\text { TABLE } 4 \\
\text { and ESS, PQSI, BDI } \\
\text { Intervention group }\end{array}$}} & \multirow{2}{*}{\multicolumn{2}{|c|}{ Control group }} \\
\hline & & & & \\
\hline & \multicolumn{4}{|c|}{ VAS } \\
\hline & $\mathrm{r}$ & $p$ & $\mathrm{r}$ & $p$ \\
\hline ESS & 0.76 & $<0.001$ & 0.88 & $<0.001$ \\
\hline PSQI & 0.47 & 0.035 & 0.82 & $<0.001$ \\
\hline BDI & 0.42 & 0.06 & 0.34 & 0.14 \\
\hline WOMAC & 0.83 & $<0.001$ & 0.88 & $<0.001$ \\
\hline Physical function & -0.03 & 0.89 & -0.34 & 0.14 \\
\hline Role physical & 0.17 & 0.48 & 0.04 & 0.88 \\
\hline Pain & 0.40 & 0.08 & -0.31 & 0.19 \\
\hline General health & -0.04 & 0.85 & 0.10 & 0.68 \\
\hline Vitality & 0.29 & 0.21 & -0.04 & 0.86 \\
\hline Social function & 0.09 & 0.72 & -0.27 & 0.24 \\
\hline Role emotion & -0.18 & 0.46 & -0.18 & 0.45 \\
\hline Mental health & 0.19 & 0.43 & 0.32 & 0.16 \\
\hline
\end{tabular}




\begin{tabular}{|c|c|c|c|c|c|c|c|c|}
\hline \multicolumn{9}{|c|}{$\begin{array}{r}\text { TABLE } 5 \\
\text { The correlations between ESS, PQSI, BDI, WOMAC and Pai }\end{array}$} \\
\hline & \multicolumn{2}{|c|}{ ESS } & \multicolumn{2}{|c|}{ PQSI } & \multicolumn{2}{|c|}{ BDS } & \multicolumn{2}{|c|}{ WOMAC } \\
\hline & $\mathrm{r}$ & $p$ & $\mathrm{r}$ & $p$ & $\mathrm{r}$ & $p$ & $\mathrm{r}$ & $p$ \\
\hline \multicolumn{9}{|c|}{ Intervention group } \\
\hline ESS & 1.00 & & & & & & & \\
\hline PSQI & 0.70 & 0.001 & 1.00 & & & & & \\
\hline BDI & 0.39 & 0.09 & 0.62 & 0.003 & 1.00 & & & \\
\hline WOMAC & 0.45 & 0.046 & 0.19 & 0.41 & 0.36 & 0.11 & 1.00 & \\
\hline Pain & 0.18 & 0.44 & 0.09 & 0.71 & 0.14 & 0.55 & 0.51 & 0.022 \\
\hline \multicolumn{9}{|c|}{ Control group } \\
\hline ESS & 1.00 & & & & & & & \\
\hline PSQI & 0.78 & $<0.001$ & 1.00 & & & & & \\
\hline BDI & 0.27 & 0.25 & 0.44 & 0.05 & 1.00 & & & \\
\hline WOMAC & 0.72 & $<0.001$ & 0.64 & 0.002 & 0.29 & 0.21 & 1.00 & \\
\hline Pain & -0.18 & 0.45 & -0.27 & 0.25 & -0.17 & 0.47 & -0.25 & 0.28 \\
\hline
\end{tabular}

program and a 65-year-old female patient needed to receive $1,000 \mathrm{mg} /$ day from the seventh day of exercise program). None of the patients complained about symptoms of exercise intolerance. There was no significant difference in the demographic characteristics between the groups $(\mathrm{p}>0.05)$ (Table 1).

In addition, there was no statistically significant difference in the VAS, WOMAC, PQSI, BDI, and ESS scores between the groups before the treatment. In both groups, there was a significant improvement in the VAS, WOMAC, PQSI, and ESS after the treatment. However, this improvement was significantly greater in the intervention group (VAS $[p<0.001]$, WOMAC [ $<<0.001]$, PQSI $[p<0.001]$, BDI $[p<0.001])$. Although there was an improvement in the BDI scores, it was not statistically significant. However, this improvement was slightly higher in the intervention treatment group (Table 2$)(\mathrm{p}=0.007)$.

According to the SF-36 subscale scores, there was a significant difference in the physical limitation subscale scores between the groups. After the treatment, a significant improvement was seen in the physical role limitation $(\mathrm{p}<0.001)$, pain $(\mathrm{p}<0.001)$, vitality $(\mathrm{p}<0.001)$, social function $(\mathrm{p}<0.001)$, emotional role functions $(p<0.001)$, and mental health scores $(p<0.001)$ in the intervention group $(\mathrm{p}<0.05)$ (Table 3$)$.

According to the ANCOVA results, the changes in the VAS, WOMAC, physical role limitation, vitality, mental health, and emotional role scores significantly differed between the groups $(p<0.005)$. On the other hand, changes in the ESS, BDI, emotional role functions, pain general health, and social function did not differ significantly between the groups.

Based on the correlation analysis, there was a significant relationship between the VAS scores and ESS, PQSI, BDI, WOMAC, and SF-36 scores in both groups $(\mathrm{p}<0.05)$. Correlation analysis results are shown in Table 4.

Table 5 summarized the relationship between the level of depression, sleep quality, and daytime sleepiness. In both groups, there was a correlation between the ESS, PSQI and WOMAC. In the treatment and control group, there was a correlation between the PSQI and BDI and between the PSQI and WOMAC, respectively.

\section{DISCUSSION}

In the present study, we evaluated the effect of physical therapy modalities on pain, sleep, mental status, and QoL of patients with OA. Our study results showed that physical therapy modalities used in the treatment of knee OA had a positive effect on sleep quality. The modalities such as HP, US, TENS, and exercise were shown to be effective as evidenced by the improvements in the VAS, BDI, WOMAC, SF-36, ESS, and PQSI scores. In addition, physical treatment modalities with additional exercise was found to be more effective on sleep quality than exercise alone. 
Sleep problems are common in arthritis patients. Power et al. ${ }^{[24]}$ reported that the rates of insomnia and non-relaxing sleep were $24.8 \%$ and $11.9 \%$, respectively in arthritis patients. Knee OA patients are also prone to sleep disorders. Allen et al. ${ }^{[25]}$ showed increased insomnia or reduced sleep quality in symptomatic hip or knee OA patients. Hawker et al. ${ }^{[26]}$ also found that $66 \%$ of knee and hip OA patients had sleep disorders. Wilcox et al. ${ }^{[27]}$ included $429 \mathrm{knee}$ OA patients and reported problems with sleep onset (31\%), sleep maintenance (81\%), and early morning awakenings (51\%) occurred at least weekly. Sariyildiz et al. ${ }^{[28]}$ also included 52 knee OA patients and found significantly higher subjective sleep quality, falling asleep period, and usual sleep habit, and total PSQI scores in the patient group compared to the controls. In our study, consistent with these findings, we also observed that both groups had significantly worse sleep quality using the PQSI scale. However, daytime sleepiness did not significantly differ between the groups.

Until now, factors affecting sleep disorders in $\mathrm{OA}$ patients have been investigated in a number of studies. Parmalee et al. ${ }^{[29]}$ reported that the main factors associated with sleep disorders in OA patients were pain and mental health status. Murphy et al. ${ }^{[30]}$ found a relationship between pain with fatigue, sleep disorders, and depression in knee OA patients. In another study, nocturnal insomnia was found to be correlated with daytime pain, although the authors were unable to find a relationship between sleep disorders and pain felt on the next day and speculated that pain must be accumulated for a few days to affect the sleep quality. ${ }^{[31]}$ Hawker et al. ${ }^{[26]}$ observed a significant correlation between sleep disorders in knee and hip OA patients with arthritis severity, pain, and depressive symptoms. Another study also showed that nocturnal pain and sleep disorder prevalence increased with knee OA severity. ${ }^{[32]}$ Taken together, we can conclude that sleep disorders in knee OA patients are related to OA severity, pain, and depression. These results indicate a close relationship between pain and sleeping disorders in knee OA patients. In our study, we also observed a relationship between the VAS and sleep scale scores, consistent with previous findings. We found worsened sleep quality and increased daytime sleepiness in the patients experiencing pain. Therefore, we can speculate that pain control may be beneficial in sleep disorders in knee OA patients.

In the literature, there is a limited number of studies evaluating the effectiveness of physical therapy modalities in knee OA patients. The TENS is a frequently used, cost-effective, easily accessible, and non-invasive treatment method used in a variety of conditions with pain. ${ }^{[33,34]}$ It reduces pain both during activity and rest and improves functional healing. ${ }^{[35]}$ It is also helpful in reducing dosage of medications used for pain control, effectively reducing undesirable side effects. ${ }^{[5]}$ In previous studies examining the effectiveness of TENS, an improvement in pain with TENS application was shown, despite the heterogeneity between the studies and their relatively short follow-up period. ${ }^{[35-37]}$ A study reported that heat and US applications did not provide enough evidence for efficacy in reducing pain, ${ }^{[37]}$ whereas another study found that therapeutic US was a beneficial and safe treatment modality for reducing pain and improving function in patients with knee OA. ${ }^{[38]}$ Zeng et al. ${ }^{[39]}$ also demonstrated that pulsed US was beneficial in reducing pain and improving function in knee OA patients, whereas continuous US was only effective in reducing pain. ${ }^{[39]}$ In our study, a significant improvement was observed in the post-treatment VAS and WOMAC scores showing functional status in the intervention group who were treated with physical therapy modalities compared to the exercise alone group. We believe that improvement in pain and functional status using physical therapy modalities caused this significant improvement in sleep quality in the intervention group.

In knee OA patients, traditional exercise modalities such as strengthening, aerobic, and flexibility exercises were shown to cause an improvement in joint symptoms, QoL, mental health, sleep, and fatigue-related parameters. ${ }^{[40]}$ The Ottawa Panel Clinical Practice Guidelines for the management of knee OA state that strength exercises cause a significant improvement in pain, function, and QoL parameters. ${ }^{[41]}$ The effects of treatments which include general exercise are usually mid-to-long term. ${ }^{[37]}$ Although there is no consensus on the exercise intensity and frequency parameters in knee OA patients, a recent systematic review reported that a total 24 exercise sessions in a 8-12 week period was very effective in knee OA patients, while a once-a-week exercise did not have any effect at all. ${ }^{[42]}$ An improvement in pain, functional status, sleep quality, and daytime sleepiness parameters were also seen in the exercise group in our study. However, this improvement was relatively low, compared to the patients treated with physical therapy modalities combined with exercise. Reduced pain and improved function with exercise might have increased the sleep quality; however, this improvement was significantly greater in the intervention group.

In their study, Sasaki et al. ${ }^{[32]}$ reported that nocturnal pain and sleep problems increased with 
knee OA severity, adversely affecting the QoL of patients. Consistent with these results, we also found that both groups had disease-related sleep disorders and impaired QoL. After the treatment, each subscale of SF-36 showed an improvement by the resolution of sleep disorders. A systematic review also showed that physical activity had a positive correlation with the QoL. ${ }^{[43]}$ In our study, similarly, we observed an improvement in the QoL in the exercise group; however, this improvement was more pronounced in the intervention group. Based on these findings, we suggest that improvement in sleep quality improves QoL of knee OA patients. However, in a study by Mesci et al. ${ }^{[44]}$ on 55 knee OA patients, physical activity improved the SF-36 scores, although sleep quality remained changed with physical activity.

Furthermore, a recent study with a large number of patients demonstrated the positive effect of balneotherapy and physical therapy on sleep quality in patients with knee OA. ${ }^{[45]}$ In this study, sleep and functional status were assessed at baseline and after a combined therapy (balneotherapy and physical therapy) using the PSQI and WOMAC. The patients scored higher on the PSQI at baseline than at one month. Consistent with this study, we also demonstrated the positive effect of physical therapy on sleep quality and functional status. On the other hand, including a control group and investigating only the effect of the physical therapy modalities rather than a combined therapy are the main strengths of the present study.

Nonetheless, there are limitations to our study. For inter-group comparisons, some of the variables lost their significance after multivariate adjustment, probably due to our relatively small sample size. However, significance for intra-group comparisons remained unchanged. Other limitation is the assessment of sleep disorders after the treatment in the short-term and according to the patient input. Therefore, larger series with longer follow-up using more objective assessment of the patient status are needed to confirm these findings. Despite these limitations, given the fact that there are few studies discussing the effect of physical therapy modalities on sleep disorders seen in knee OA patients, the present study is valuable as it provides a significant contribution to the limited body of knowledge on this topic in the literature.

In conclusion, exercise and physical therapy modalities have positive effects on pain, functional status, depression, QoL, and sleep quality. Exercise treatment combined with physical therapy modalities can yield a more significant improvement in pain, functional status, sleep quality, and QoL. Based on our study findings, we conclude that exercise treatment combined with physical therapy modalities can improve the sleep quality in knee OA patients.

\section{Declaration of conflicting interests}

The authors declared no conflicts of interest with respect to the authorship and/or publication of this article.

\section{Funding}

The authors received no financial support for the research and/or authorship of this article.

\section{REFERENCES}

1. Murphy L, Schwartz TA, Helmick CG, Renner JB, Tudor $\mathrm{G}$, Koch G, et al. Lifetime risk of symptomatic knee osteoarthritis. Arthritis Rheum 2008;59:1207-13.

2. Cheng OT, Souzdalnitski D, Vrooman B, Cheng J. Evidencebased knee injections for the management of arthritis. Pain Med 2012;13:740-53.

3. Cakır N, Pamuk ÖN, Derviş E, Imeryüz N, Uslu H, Benian Ö, et al. The prevalences of some rheumatic diseases in western Turkey: Havsa study. Rheumatol Int 2012;32:895-908.

4. Yeşil H, Hepgüler S, Öztürk C, Çapacı K, Yeşil M. Prevalence of symptomatic knee, hand and hip osteoarthritis among individuals 40 years or older: a study conducted in İzmir city. Acta Orthop Traumatol Turc 2013;47:231-5.

5. Bjordal JM, Johnson MI, Lopes-Martins RA, Bogen B, Chow R, Ljunggren AE. Short-term efficacy of physical interventions in osteoarthritic knee pain. A systematic review and meta-analysis of randomised placebo-controlled trials. BMC Musculoskelet Disord 2007;8:51.

6. Hutchings A, Calloway M, Choy E, Hooper M, Hunter DJ, Jordan JM, et al. The Longitudinal Examination of Arthritis Pain (LEAP) study: relationships between weekly fluctuations in patient-rated joint pain and other health outcomes. J Rheumatol 2007;34:2291-300.

7. Hawker GA, French MR, Waugh EJ, Gignac MA, Cheung C, Murray BJ. The multidimensionality of sleep quality and its relationship to fatigue in older adults with painful osteoarthritis. Osteoarthritis Cartilage 2010;18:1365-71.

8. Cetin N, Aytar A, Atalay A, Akman MN. Comparing hot pack, short-wave diathermy, ultrasound, and TENS on isokinetic strength, pain, and functional status of women with osteoarthritic knees: a single-blind, randomized, controlled trial. Am J Phys Med Rehabil 2008;87:443-51.

9. Cheing GL, Tsui AY, Lo SK, Hui-Chan CW. Optimal stimulation duration of tens in the management of osteoarthritic knee pain. J Rehabil Med 2003;35:62-8.

10. Goren A, Yildiz N, Topuz O, Findikoglu G, Ardic F. Efficacy of exercise and ultrasound in patients with lumbar spinal stenosis: a prospective randomized controlled trial. Clin Rehabil 2010;24:623-31. 
11. Farr JN, Going SB, McKnight PE, Kasle S, Cussler EC, Cornett M. Progressive resistance training improves overall physical activity levels in patients with early osteoarthritis of the knee: a randomized controlled trial. Phys Ther 2010;90:356-66.

12. White D, Evans JA, Truscott JG, Chivers RA. Can ultrasound propagate in the joint space of a human knee? Ultrasound Med Biol 2007;33:1104-11.

13. Tascioglu F, Kuzgun S, Armagan O, Ogutler G. Short-term effectiveness of ultrasound therapy in knee osteoarthritis. J Int Med Res 2010;38:1233-42.

14. Doruk P, Adam M, Leblebici B, Pektaş Ö. The effects of physical medicine and rehabilitation modalities on muscle strength and postural stability of primary knee osteoarthritis. J PMR Sci 2013;16:55-61.

15. Verkleij SP, Luijsterburg PA, Willemsen SP, Koes BW, Bohnen AM, Bierma-Zeinstra SM. Effectiveness of diclofenac versus paracetamol in knee osteoarthritis: a randomised controlled trial in primary care. Br J Gen Pract 2015;65:e530-7.

16. Kellgren JH, Lawrence JS. Radiological assessment of osteoarthrosis. Ann Rheum Dis 1957;16:494-502.

17. Boonstra AM, Schiphorst Preuper HR, Reneman MF, Posthumus JB, Stewart RE. Reliability and validity of the visual analogue scale for disability in patients with chronic musculoskeletal pain. Int J Rehabil Res 2008;31:165-9.

18. Bellamy N, Buchanan WW, Goldsmith $\mathrm{CH}$, Campbell J, Stitt LW. Validation study of WOMAC: a health status instrument for measuring clinically important patient relevant outcomes to antirheumatic drug therapy in patients with osteoarthritis of the hip or knee. J Rheumatol 1988;15:1833-40.

19. Basaran S, Guzel R, Seydaoglu G, Guler-Uysal F. Validity, reliability, and comparison of the WOMAC osteoarthritis index and Lequesne algofunctional index in Turkish patients with hip or knee osteoarthritis. Clin Rheumatol 2010;29:749-56.

20. Beck AT, Ward CH, Mendelson M, Mock J, Erbaugh J. An inventory for measuring depression. Arch Gen Psychiatry 1961:561-71.

21. Ağargün MY, Kara H, Anlar Ö. The Validity and Reliability of the Pittsburgh Sleep Quality Index. Turkish Journal of Psychiatry 1996;7:107-11.

22. Johns MW. A new method for measuring daytime sleepiness: the Epworth sleepiness scale. Sleep 1991;14:540-5.

23. Ware JE Jr, Kosinski M, Bayliss MS, McHorney CA, Rogers WH, Raczek A. Comparison of methods for the scoring and statistical analysis of SF-36 health profile and summary measures: summary of results from the Medical Outcomes Study. Med Care 1995;33:AS264-79.

24. Power JD, Perruccio AV, Badley EM. Pain as a mediator of sleep problems in arthritis and other chronic conditions. Arthritis Rheum 2005;53:911-9.

25. Allen KD, Renner JB, Devellis B, Helmick CG, Jordan JM. Osteoarthritis and sleep: the Johnston County Osteoarthritis Project. J Rheumatol 2008;35:1102-7.

26. Hawker GA, Mian S, Bednis K, Stanaitis I. Osteoarthritis year 2010 in review: non-pharmacologic therapy. Osteoarthritis Cartilage 2011;19:366-74.
27. Wilcox S, Brenes GA, Levine D, Sevick MA, Shumaker SA, Craven T. Factors related to sleep disturbance in older adults experiencing knee pain or knee pain with radiographic evidence of knee osteoarthritis. J Am Geriatr Soc 2000;48:1241-51.

28. Sarıyıldız MA, Batmaz İ, Kaya MC, Bozkurt M, Okçu M, Yildiz M, et al. Association of the sleep quality with pain, radiological damage, functional status and depressive symptoms in patients with knee osteoarthritis. J Clin Exp Invest 2013;4:189-4.

29. Parmelee PA, Tighe CA, Dautovich ND. Sleep disturbance in osteoarthritis: linkages with pain, disability, and depressive symptoms. Arthritis Care Res 2015;67:358-65.

30. Murphy SL, Lyden AK, Phillips K, Clauw DJ, Williams DA. Association between pain, radiographic severity, and centrally-mediated symptoms in women with knee osteoarthritis. Arthritis Care Res 2011;63:1543-9.

31. Martire LM, Keefe FJ, Schulz R, Parris Stephens MA, Mogle JA. The impact of daily arthritis pain on spouse sleep. Pain 2013; 154:1725-31

32. Sasaki E, Tsuda E, Yamamoto Y, Maeda S, Inoue R, Chiba $\mathrm{D}$, et al. Nocturnal knee pain increases with the severity of knee osteoarthritis, disturbing patient sleep quality. Arthritis Care Res 2014;66:1027-32.

33. King EW, Sluka KA. The effect of varying frequency and intensity of transcutaneous electrical nerve stimulation on secondary mechanical hyperalgesia in an animal model of inflammation. J Pain 2001;2:128-33.

34. Chen CC, Johnson MI. An investigation into the hypoalgesic effects of high- and low-frequency transcutaneous electrical nerve stimulation (TENS) on experimentally-induced blunt pressure pain in healthy human participants. J Pain 2010;11:53-61.

35. Cherian JJ, Jauregui JJ, Leichliter AK, Elmallah RK, Bhave A, Mont MA. The effects of various physical non-operative modalities on the pain in osteoarthritis of the knee. Bone Joint J 2016;98-B(1 Suppl A):89-94.

36. Chen LX, Zhou ZR, Li YL, Ning GZ, Li Y, Wang XB, et al. Transcutaneous electrical nerve stimulation in patients with knee osteoarthritis: Evidence from randomized-controlled trials. Clin J Pain 2016;32:146-54.

37. Newberry SJ, FitzGerald J, SooHoo NF, Booth M, Marks J, Motala A, et al. Treatment of Osteoarthritis of the Knee: An Update Review [Internet]. Rockville (MD): Agency for Healthcare Research and Quality (US); 2017 May. Report No.: 17-EHC011-EF.

38. Zhang C, Xie Y, Luo X, Ji Q, Lu C, He C, et al. Effects of therapeutic ultrasound on pain, physical functions and safety outcomes in patients with knee osteoarthritis: a systematic review and meta-analysis. Clin Rehabil 2016;30:960-71.

39. Zeng C, Li H, Yang T, Deng ZH, Yang Y, Zhang Y, et al. Effectiveness of continuous and pulsed ultrasound for the management of knee osteoarthritis: a systematic review and network meta-analysis. Osteoarthritis Cartilage 2014;22:1090-9.

40. Wellsandt E, Golightly Y. Exercise in the management of knee and hip osteoarthritis. Curr Opin Rheumatol 2018;30:151-9. 
41. Brosseau L, Taki J, Desjardins B, Thevenot O, Fransen M, Wells GA, et al. The Ottawa panel clinical practice guidelines for the management of knee osteoarthritis. Part two: strengthening exercise programs. Clin Rehabil 2017;31:596-611.

42. Young JL, Rhon DI, Cleland JA, Snodgrass SJ. The Influence of exercise dosing on outcomes in patients with knee disorders: a systematic review. J Orthop Sports Phys Ther 2018;48:146-61.

43. Klavestrand J, Vingård E. The relationship between physical activity and health-related quality of life: a systematic review of current evidence. Scand J Med Sci Sports 2009;19:300-12.

44. Mesci E, Icagasioglu A, Mesci N, Turgut ST. Relation of physical activity level with quality of life, sleep and depression in patients with knee osteoarthritis. North Clin Istanb 2015;2:215-21.

45. Kaya E, Kaplan C, Çarli AB, Güzelküçük Ü. Effects of Balneotherapy and Physical Therapy on Sleep Quality in Patients with Osteoarthritis Aged 50 to 85 Years. Arch Rheumatol 2015;31:1-5. 